\title{
Современное состояние горно-лесных почв в бассейне реки Зеямчай и горно-черноземных почв около села Дюзюрт
}

\author{
3.И. Эюбова \\ Институт географии им. акад. Г. А. Алиева Наџиональной академии наук Азербайджана, \\ Азербайджанская Республика (AZ1143, г. Баку, просп. Г. Джавида, 115) \\ Поступила в редакиию 16.07.2019 \\ Принята к публикации 26.02.2020
}

\begin{abstract}
Аннотация: Цель - разработка научной основы предотвращения деградации горно-лесных и горно-черноземных почв и пути их восстановления на исследуемых территориях. В статье рассматриваются естественные и антропогенные деградации горно-бурых лесных почв под буковым лесом, горнокоричневых лесных почв под грабовым и дубовым лесами в бассейне Зеямчай и карбонатных черноземных почв около села Дюзюрт. Рельеф исследуемых территорий сильно эрозионно-опасный, представлен расчлененными низкогорьями, среднегорьями и горными котловинами, изрезанные горными реками. В этих зонах почвы распространяются на сухих низкогорьях и в верхнюю увлажненную часть среднегорья. Результаты и обсуждение. Выяснено влияние некоторых свойств почвы на рост и развитие древесных пород в лесных ценозах. На исследуемых территориях заложены почвенные разрезы. Изучено влияние высоты, крутизны и экспозиции склонов, состава лесного покрова, литологического состава почвообразующих пород и физико-химического состава почвы на интенсивность процесса деградации. Кроме того, физико-химический состав этих почв по почвенному профилю анализируется в сравнении с анализом предыдущих годов (1966-1990).
\end{abstract}

Ключевые слова: почва, плодородие, деградация, почвенный горизонт.

\section{Current State of Mountain Forest Soils in the Pool Zeyamchay and Mountain- Black Soils near the Village of Dyuzyurt}

\section{Z. I. Eyubova网}

Abstract: In this article discusses the natural and anthropogenic degradation of mountain-brown forest soils under a beech forest, and of mountain-brown forest soils under hornbeam oak forests in the Zeyemchay basin and carbonate black soils near the village of Dyuzyurt. The relief of the investigated territories highly erosion-hazardous, represented from the strongly dissected lowlands, middle mountains and mountain-gorge basins, quite densely indented by mountain rivers. In these zones, soils spread in the dry lowlands and in the upper moistened part of the middle mountains. The planet needs the rational use of forest resources in order to combat erosion and soil conservation. Soils provide the basis for the growth of trees and entire forests. Soils are an essential component of forests and forest ecosystems because they are involved in the regulation of important ecosystem processes such as nutrient uptake, decomposition, and water balance. By reducing the risk of soil erosion and the threat of landslides and avalanches, the rational use of forest resources greatly contributes to the functioning of systems responsible for maintaining clean water reserves on the planet, as well as a balanced water cycle. Soils give trees rooting opportunities and, in turn, forest trees, as well as other plants and vegetation, are important factors in protecting soil cover. Therefore, the effect of some of the soil properties on the growth and development of tree species in forest cenotes has been clarified. In the studied territories, soil sections were laid. The influence of the height, incline, exposure of the slopes, the composition of the forest cover, the lithological composition of the parent rocks and the physicochemical composition of the soil, and other factors on the intensity of the degradation process was studied. In addition, the physico-

() Эюбова 3.И., 2020

¿ E-mail: zuzum30@gmail.com

(c) (i) Контент доступен под лицензией Creative Commons Attribution 4.0 License.

The content is available under Creative Commons Attribution 4.0 License. 
chemical composition of these soils along the soil profile is analyzed in comparison with the analysis of previous years (1966-1990).

Key words: mail, frosting, degradation, horizon, natural, anthropogenic.

\section{ВВЕДЕНИЕ}

XXI век человечество встречает в условиях острейшего экологического кризиса, обусловленного ограниченностью почвенных ресурсов и их интенсивным нерациональным использованием. Современная площадь пахотных почв в мире составляет 1,5 млрд. гектаров. Резервы расширения пашни крайне ограничены и составляют 1,2 млрд. га, из них в тропическом поясе - 870 , субтропическом - 168 , суббореальном - 80 и бореальном 82 млн. га. Однако, освоение этих почв связано с уничтожением лесов на огромных площадях в тропическом и субтропическом поясах, что в случае их освоения усугубит экологическую ситуацию на Земном шаре.

\section{МАТЕРИАЛ И МЕТОДИКА}

Леса в бассейне реки Зеямчай были подвергнуты деградации, а водно-физические свойства лесных почв ухудшились, что повлияло на уменьшение плодородия в несколько раз. То же самое произошло с горно-черноземными почвами под степями. Поэтому изучение современного состояния лесных почв становится актуальным. Полученные результаты почвенных анализов сравнивались с результатами исследовательских работ, проведенных в предыдущие годы (1960-1990). Анализ почвенных образцов проводился по следующим методикам: валовой химический состав определялся общепринятым методом (Аринушкина, 1970); общий гумус по Тюрину; водная вытяжка по Иванову; гигроскопическая влага весовым методом Николаева; поглощенные основания по Иванову; $\mathrm{CO}_{2}$ по кальцеметрической, $\mathrm{pH}$ водный потенциометрической; гранулометрический состав пипеточным методом по Качинскому, изучение процесса деградации почвы по методу $[8,1,11,12,4,9]$. На сельскохозяйственных землях деградацию почв исследовали М. Г. Ишбулатов и С. З. Чурагулова $[1,8]$.

В 2015 году нами были проведены маршрутные почвенные исследования с целью изучения современного состояния горных лесных почв в бассейне реки Зеямчай и горно-черноземных в северо-восточной части Малого Кавказа и степени их деградации в результате антропогенного воздействия. Картасхема территории была разработана на основе «Карты почв Аз. ССР», составленной в 1991 году под редакцией акад. Г. Ш. Мамедова и Г. Ш. Якубова [2].
Для определения степени деградации горнолесных почв в Гедабейском районе к западу от села Шахдаг на высоте 1500 метров над уровнем моря на северных склонах крутизной 25-30 берегу Зеямчай были заложены разрезы №7 под буковым лесом, а разрезы № 2 и № 9 на деградированных почвенных участках под луговыми травами. Разрез № 11 расположен на правом берегу Зеямчай на северо-запад от села Гызылторпаг на абсолютной высоте 950 м на северном склоне крутизной $25-30^{\circ}$ под грабовым лесом и разрез № 13 на той же высоте на 50 м к востоку от села под луговыми травами. Разрез № 17 был заложен у села Дюзюрт на месте степной и лугово-степной растительности с уклоном поверхности $18-20^{\circ}$, где развиты горно-черноземные почвы.

\section{ОБСУЖДЕНИЕ РЕЗУЛЬТАТОВ}

Из-за частого нарушения местным населением пирогенного режима в бассейне реки Зеямчай стало невозможным использовать летние пастбища, к тому же усилился выпас скота в лесах. Незаконные рубки снижают лесистость, что также вызывает деградацию земель и провоцирует образование оползней.

Коричневые горно-лесные почвы сформированы в низкогорьях Зеямчайского бассейна под грабовыми лесами на высоте 800-1000 м. Рельеф высотного пояса представлен холмистонизкогорными местностями и высокими плато, прорезанных горными реками. Почвы формируются в сухом климате при жарком лете и мягкой зиме. Почвообразующие породы состоят из вулканических брекчий, известняков, известковых песчаников, карбонатных глинистых сланцев, элювиальных и элювиальноделювиальных продуктов коры выветривания.

Как видно из таблицы 1 , общее количество гумуса в профиле горно-коричневых лесных почв под грабовым лесом составляет 1,2-5,2\%, а его высокое содержание $(3,2-5,2 \%)$ сосредоточено в гумусовом горизонте. По профилю почвы количество гумуса уменьшалось до 0,9-1,2\%. Общие запасы гумуса в этих почвах составляют 227,5 т/га, потери составили - 90,8 т/га, а толщина гумусового слоя уменьшилась на 1-2 см по сравнению с предыдущими годами. Общие потери гумуса в границах этих почв были рассчитаны путем сравнения данных [7] за 1983 год. Содержание общего азота доходит до $0,23-0,30 \%$, отношения $\mathrm{C}: \mathrm{N}$ ко- 
Современное состояние горно-лесных почв в бассейне реки Зеямчай и горно-черноземных почв около села Дюзюрт

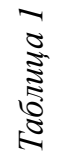

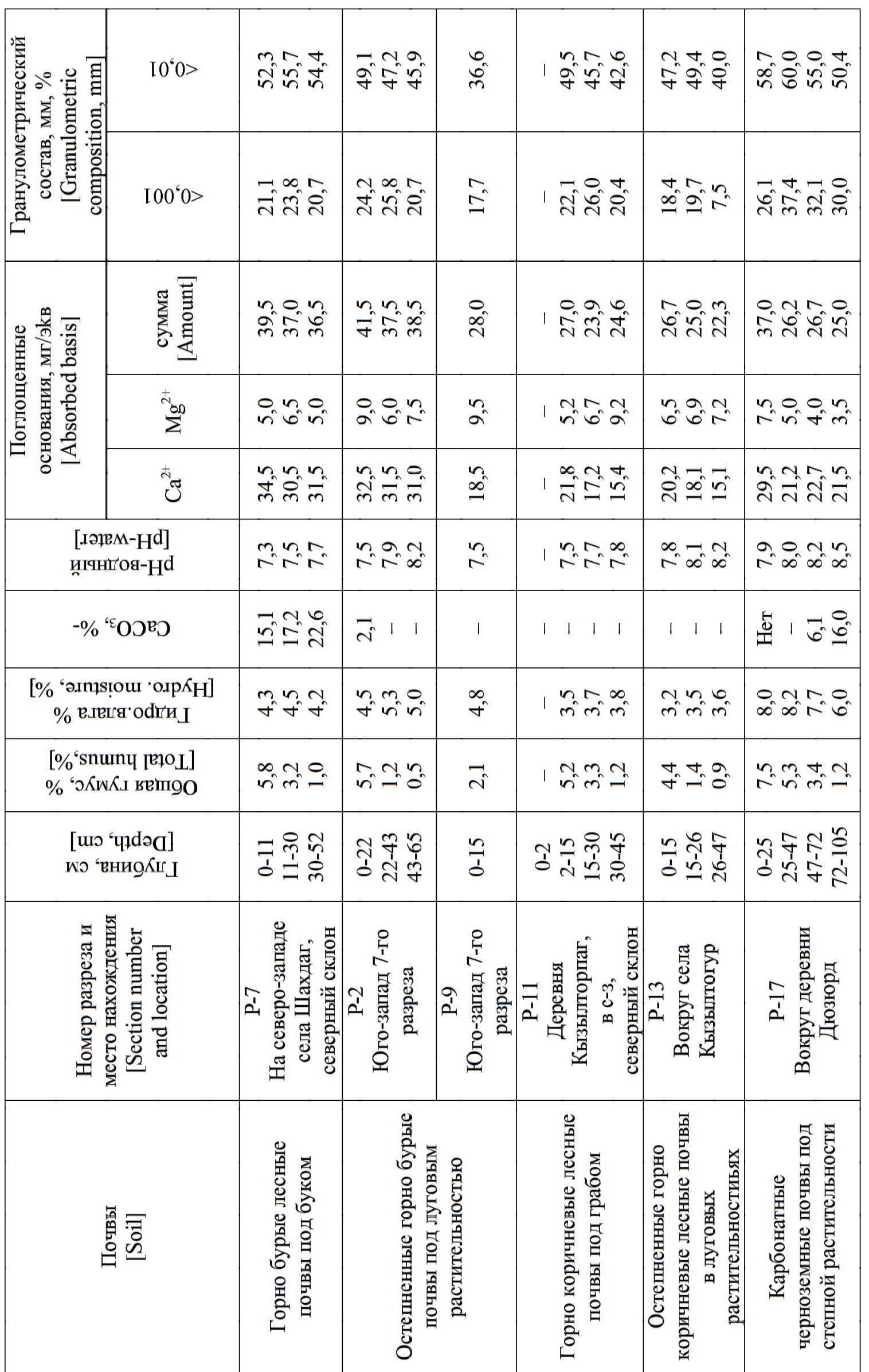


леблется от 7,6-12,2. Количество гигроскопической влаги в этих почвах изменяется в пределах $3,2-3,8 \%$.

В профиле коричнево горно-лесных почв кальций и карбонаты не найдены. Почва имеет нейтральную и слабощелочную (pH 7,0-7,5) среду. Количество поглощенных оснований в профиле почв варьирует от 23,9 до 27,0 мг/экв., а высокое содержание 27,0 мг/экв. в верхнем слое (таблица 1). Количество катионов кальция в поглощенном комплексе изменяется от 15,4 до 21,8 мг/ экв., а высокое количество (21,8 мг/экв.) отмечается в гумусовом горизонте. Количество катиона магния находится между 5,2-9,2 мг/экв. и уменьшается по профилю почвы. Как видно из таблицы 1, в профиле коричнево горно-лесных почв гранулометрический состав относится к тяжело суглинистой фракции. Количество физической глины колеблется в пределах 45,7-49,5\% и высокое ее содержание отмечено в гумусовом и элювиальном горизонтах. В настоящее время коричнево горно-лесные почвы по гранулометрическому составу деградированы и тяжело суглинистый гранулометрический состав сменяется средне суглинистым.

Как видно из таблицы 1 , общее содержание гумуса в профиле остепненных коричнево горнолесных почв колеблется в пределах 0,9-4,4\%, а максимум его $(4,4 \%)$ отмечается в верхнем слое (0-15 см). Этот показатель резко уменьшается по профилю почвы и составляет $0,9 \%$ в нижнем слое. В профиле остепненных коричнево горно-лесных почв содержание $\mathrm{CaCO}_{3}$ не наблюдается. Существует слабая щелочная среда $(\mathrm{pH} 7,5)$ в верхнем 0-15 см слое этих почв и повышается щелочность по всему профилю. Количество поглощенного обменного основания в профиле коричневых горнолесных почв колеблется от 22,3 до 26,7 мг/экв., а его высокое содержание (25,0-26,7 мг/экв.) обнаружено в верхних слоях. Катионы кальция в комплексе являются преобладающими, и их количество колеблется в пределах 15,1-20,2 мг/экв. Высокие количества катиона кальция (18,1-20,2 мг/экв.) были обнаружены в верхних слоях. Катионы магния колеблются в пределах 6,5-7,2 мг/экв. (таблица 1). Гранулометрический состав остепненных коричнево горно-лесных почв ранее был тяжело суглинистым, а в настоящее время на деградированных участках встречается среднесуглинистый гранулометрический состав.

Общие запасы гумуса на глубине 0-30 см антропогенно-остепненных участках коричнево горно-лесных почв составляют 133,0-227,0 т/га, а средне гранулометрический состав и водостойкие агрегаты равны $50 \%$. Это свидетельствует о наличии благоприятных почвенных условий для восстановления грабово-дубовых лесов.

Горные буро-лесные почвы. Почвы распространены в бассейне реки Зеямчай на высоте 10002000 м над уровнем моря под буковыми лесами. Рельеф сильно эрозионно-опасный представлен сильно расчлененными среднегорьями и горноущельевыми котловинами, густо изрезанные горными реками. Почвы сформированы на делювии слабо выветренных горных пород, особенно на продуктах выветривания юрских песчаников, диоритовых, известняковых и глинистых сланцах. Горные буро-лесные почвы формируются в умеренно-теплом, влажном климате.

На этой высоте климат благоприятен для роста буковых, буково-грабовых и дубово-грабовых насаждений с примесью клена и ясеня, образуя плотный лесной полог, сильно затеняющий поверхность почвы. В бассейне реки Зеямчай физикохимические свойства горных буро-лесных почв изучены М.Э. Салаевым [5, 6], Г. А. Саламовым [7], Ш.И. Мирзоевым [4], 3. Р. Мамедовым [3]. М. Э. Салаев [6] и Г. А. Саламов [7] в северо-восточной части Малого Кавказа по физико-химическим свойствам среди горно-бурых лесных почв выделяет следующие подтипы: 1) горно-бурые лесные типичные; 2) горно-бурые лесные остаточнокарбонатные; 3 ) горно-бурые лесные неполноразвитые; 4) горно-бурые лесные остепненные.

В бассейне Зеямчай под буковым лесом сформировались горно-лесные бурые типичные подтипы. Как видно из таблицы 1 , в гумусовом слое горно-бурых лесных почв количество гумуса варьирует от $3,2 \%$ до 5,8\%, а его содержание по всему профилю резко уменьшается до - $1,0 \%$. Общие запасы гумуса в слое 0-50 см горно буро-лесной почвы в 2015 году составили 340 т/га, а его потеря равна 110 т/га по сравнению с предыдущими годами. Потеря запасов гумуса в этих почвах определялась по результатам анализа Г. А. Саламова в 1983 году. В настоящее время лесная подстилка полностью вымыта на вышеупомянутых лесных почвах и сохраняется только в долинах. Однако, согласно данным Г. А. Саламова [7] в 1983 году толщина слоя лесной подстилки составляла $3 \mathrm{~cm}$ на поверхности этих почв, распространяющихся вокруг села Арабачи на левом берегу Зеямчай.

Содержание гумуса в почве характеризуется резким уменьшением гумусового слоя, промывкой лесной подстилки. Гумусовый слой разрушается в результате неконтролируемого выпаса скота в 
лесах. Содержание $\mathrm{CaCO}_{3}$ в почвенном профиле колеблется от 15,0 до $22,5 \%$, а максимальное его количество отмечается в гумусовом горизонте (таблица 1$)$.

Горные буро-лесные почвы по гранулометрическому составу относятся к тяжелосуглинистой фракции, где содержание физической глины варьирует между 52,3-55,7\% под лесами, а ее высокое количество определяется в элювиальном горизонте. В профиле деградированных горно-лесных почв гранулометрический состав среднесуглинистый.

В последние годы (2000-2018) отмечается активизация оползней на северном и северо-западном склоне хребта Шахдаг. В 2004 и 2009 годах на северо-востоке села Шахдаги Гедабексого района произошло оползание на площади 2-3 гектара под горными буро-лесными почвами с лесным покровом. Причина - антропогенная деградация почвы.

Горные черноземные почвы образуются на горном плато, степном нагорье и подгорных равнинах. Обычно на сильно расчлененных и хорошо дренированных территориях на высоте 800-1600 м. В северо-восточной части Малого Кавказа они развиваются под злаково-разнотравными степями. Почвообразующими породами выступают делювиальные карбонатные суглинки или продукты выветривания известняков и известняковых песчаников. Важным условием для образования чернозема является относительно продолжительный период с благоприятными гидротермическими условиями - сухое жаркое лето, продолжительная осень и умеренная зима. Среднегодовая температура воздуха составляет $8,4-10,8^{\circ} \mathrm{C}$, а температура холодного месяца $0,8-3,4^{\circ} \mathrm{C}$. Почва в таком случае не промерзает, хотя снеговой покров неустойчив. Среднегодовое количество осадков изменяется в пределах 450-600 мм. Осадки выпадают в основном весной и осенью. Коэффициент увлажнения равен $-0 ;-1,1$.

М.Э. Салаев [6] в Республике Азербайджан горно-черноземные почвы разделил на следующие подтипы: черноземы выщелоченные; черноземы обыкновенные; черноземы карбонатные и черноземы слитые.

Карбонатные горно-черноземные почвы изучены на Малом Кавказе М.Э. Салаевым [5], Ш.И. Мирзоевым [4], 3. Р. Мамедовым [3].

Результаты анализа 2015 года показывают, что общее количество гумуса в профиле горно-черноземных почв колеблется от 1,2 до 7,5\%, а его максимальное количество определено в гумусовом горизонте 5,3-7,5\%. Общие запасы гумуса в гуму- совом слое этих почв сократилось на 50-60 т/га. Уменьшение общих запасов гумуса было рассчитано на основе данных М.Э. Салаева [6] в 1991 году (таблица 2). Содержание карбоната кальция изменяется от 6,1 до $16,0 \%$ и сосредоточены в нижних горизонтах (таблица 1).

Величина рН в гумусном слое горно-черноземных почв колеблется около 7,9-8,5, а в нижнем слое она равна - 8,5 (таблица 1). В предыдущие годы в верхних горизонтах отмечалась нейтральная $(\mathrm{pH} 7,0)$ почвенная среда. Из таблицы 2 видно, что в профиле горно-черноземных почв преобладает тяжело суглинистый гранулометрический состав. Количество физической глины колеблется от 50,1 до 57,9\%. Данные анализа 2015 года показывают, что в гумусовом слое этих почв сохраняется тяжело суглинистый гранулометрический состав и количество физической глины в нем колеблется пределах 58,7-60,0\%.

В таблице 2 отмечено, что в горно-черноземных почвах содержание поглощенных оснований составляет 23,6-36,4 мг/экв., а большое их количество определено в гумусовым горизонте 36,4 мг/экв. В комплексе поглощенных оснований наибольше количество - 33,9 мг/экв. приходится на долю катионов кальция, а наименьшее количество на долю магния - 2,5 мг/экв. Из данных таблицы 1 видно, что в 2015 году в профиле горных черноземов количество поглощенных оснований меняется в пределах 25,0-37,0 мг/экв. В комплексе поглощенных оснований количество катионов кальция составляет 21,2-29,5 мг/экв., а катионов магния - 3,5-7,5 мг/экв.

\section{ЗАКЛЮЧЕНИЕ}

Из выше изложенных материалов на основе данных лабораторного анализа горно-лесных почв бассейна реки Зеямчай и черноземных горных почв вокруг села Дюзюрт получены следующие результаты.

1. Антропогенное воздействие на природу распространения коричневых горно-лесных почв было уменьшено, так как эта территория охраняется государством, а деревни снабжаются природным газом.

2. Земли, наиболее подверженные антропогенной деградации в бассейне реки Зеямчай, представлены коричнево горно-лесными почвами. Общие запасы гумуса в гумусном слое этих почв снижен на 70-90 т/га. Зернистая структура верхнего горизонта изменена на мелко комковатую, тяжелосуглинистый гранулометрический состав изменен на среднесуглинистый, нейтральная среда на слабо щелочную. 


\begin{tabular}{|c|c|c|c|c|c|c|}
\hline \multirow{2}{*}{ 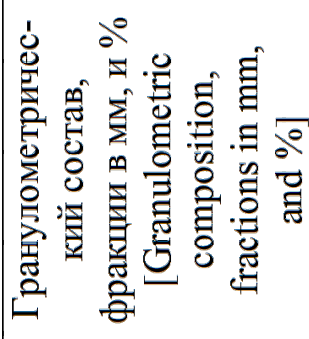 } & $\overline{\theta_{n}}$ & 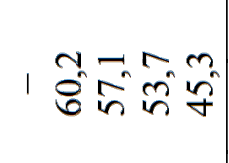 & 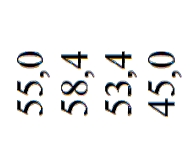 & 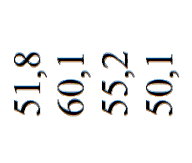 & 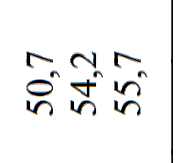 & 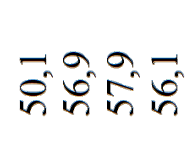 \\
\hline & $\overline{8}$ & 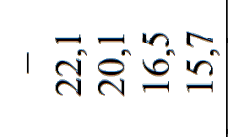 & 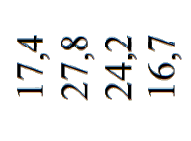 & $\begin{array}{l}m \infty \theta \tilde{n} \\
\infty \approx i \tilde{n}=\end{array}$ & 픙ำ & 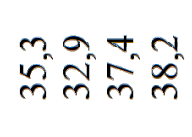 \\
\hline \multirow{3}{*}{ 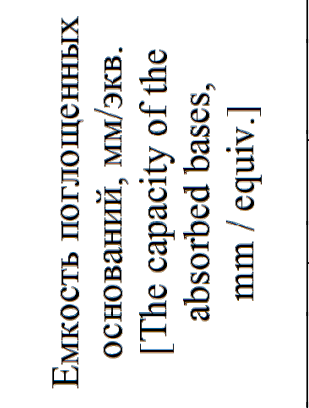 } & $\sum_{0}^{\pi}$ & 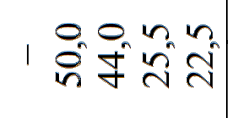 & 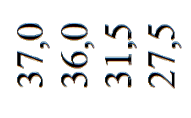 & 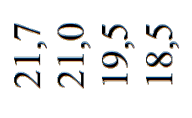 & $\begin{array}{l}\text { n. } \\
\text { ปิลี }\end{array}$ & 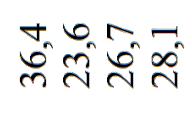 \\
\hline & $\sum^{\infty}$ & 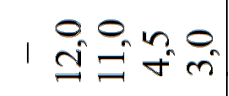 & $\begin{array}{l}0 n n n \\
0 \Leftrightarrow 0 \\
0\end{array}$ & $\begin{array}{l}n=\infty \\
0=\infty\end{array}$ & $\begin{array}{l}0, n \\
n \\
n\end{array}$ & $\begin{array}{lll}n & \infty & 0 \\
\hat{N} m & \forall & 0\end{array}$ \\
\hline & $\tilde{\mho}$ & 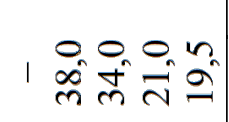 & 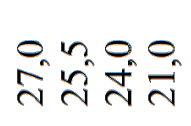 & $\begin{array}{l}\operatorname{con} n=0 \\
n=0\end{array}$ & $\begin{array}{l}n 0 n \\
n=10\end{array}$ & $\begin{array}{l}\hat{m} \boldsymbol{N} \\
\dot{m} \hat{\imath} \tilde{d}\end{array}$ \\
\hline \multicolumn{2}{|l|}{ 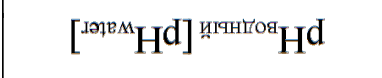 } & 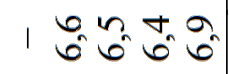 & $\begin{array}{l}n \\
n \\
n\end{array}$ & $\begin{array}{l}m \\
r \\
r\end{array}$ & केन्त & $\begin{array}{ccc}0 & 0 \\
\sim & 0 & \\
0\end{array}$ \\
\hline \multicolumn{2}{|l|}{$\%{ }^{\complement} \mathrm{O} \mathcal{O}^{\mathrm{E}} \mathcal{}$} & $\begin{array}{llll}1 & 1 & 1 & 1\end{array}$ & $\stackrel{E}{\mathbb{I}} \mid$ | 1 & 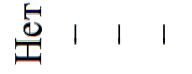 & 䓪 1 & $\stackrel{5}{ \pm}|1|$ \\
\hline \multicolumn{2}{|c|}{ 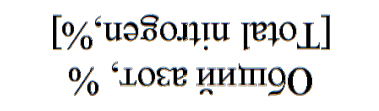 } & 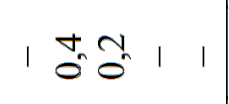 & 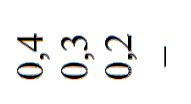 & $\begin{array}{l}n \\
2 \\
0\end{array}=$ & $\begin{array}{ll}n & 1 \\
0 & =\end{array}$ & 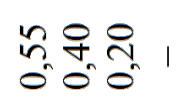 \\
\hline \multicolumn{2}{|c|}{ 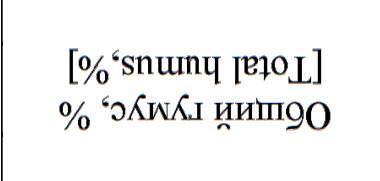 } & 承 & कीजिन & जी & 델= & ñmiñ \\
\hline \multicolumn{2}{|l|}{ 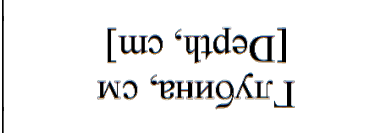 } & 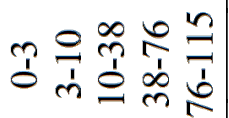 & 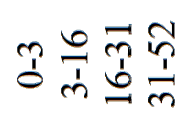 & 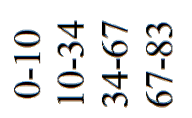 & 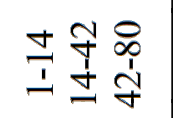 & 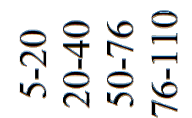 \\
\hline \multicolumn{2}{|l|}{ 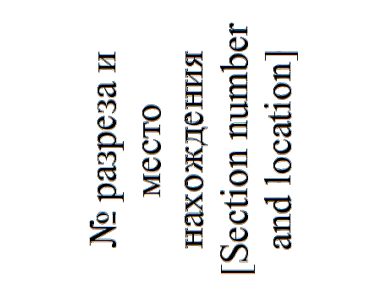 } & 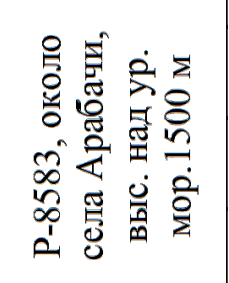 & 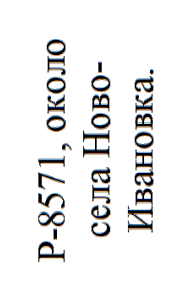 & 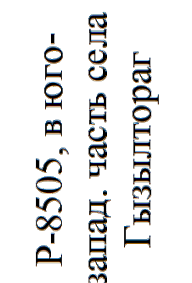 & 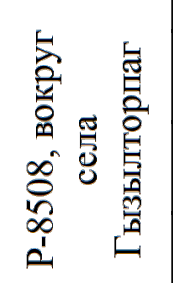 & 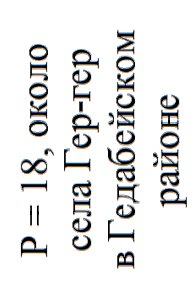 \\
\hline \multicolumn{2}{|l|}{ 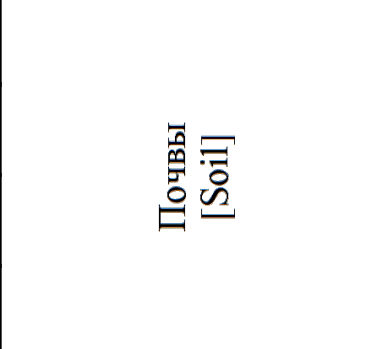 } & 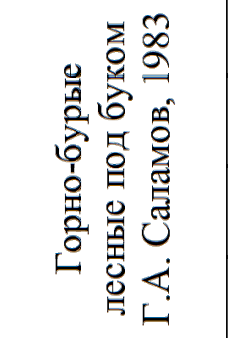 & 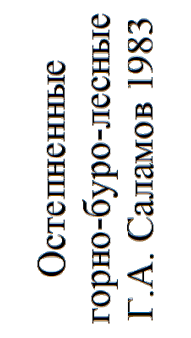 & 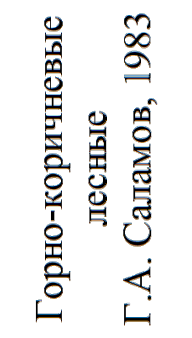 & 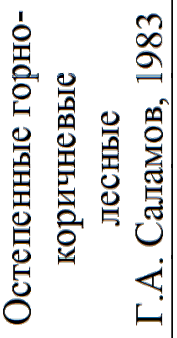 & 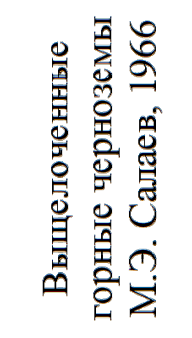 \\
\hline
\end{tabular}


3. В течение последних 50-60 лет процесс деградации сопровождался усилением антропогенного воздействия на горно бурые-лесные почвы. Мощность гумусового слоя уменьшилась до 25 см, а общее содержание гумуса снизилось до 100110 т/га. Подстилка на гумусовом слое почвы и мелкоземные частицы смыты. Зернистая структура заменена на мелко комковатую.

4. Толщина гумусового слоя в карбонатной горно-черноземной почве составляет 40-50 см и сохранение благоприятных водно-физических свойств свидетельствует о том, что в гумусовом слое этих почв наблюдается слабая и умеренная деградация. Запасы гумуса в этих почвах сократились на 5060 т/га. Почвы интенсивно используются в богарном земледелии преимущественно под зерновые, картофель и частично табак. При отсутствии строгой системы севооборотов.

\section{СПИСОК ЛИТЕРАТУРЫ}

1. Ишбулатов М. Г. [и др.] Изменение свойств почв лесной экосистемы под влиянием антропогенных нагрузок // Известия Самарского НЦ РАН, 2011, т. 13, № 1 (5), c. 1200-1203.

2. Мамедов Г.Ш., Якубов Г.Ш. Руководство по выявлению и картографированию деградированных земель, эрозии, засоления и других причин для подготовки предложений по их эффективному использованию. Баку, 2010. 113 с.

3. Мамедов 3. Р. Экологическая оценка северо-восточного склона Малого Кавказа. Баку, Наука, 2014. $206 \mathrm{c}$.

4. Мирзоев Ш. И. Исследование экологических особенностей почв горно-лесной зоны на северо-восточном склоне Малого Кавказа. (Отчет 2005-2006) НАНА складские материалы 75.

5. Салаев М.Э. Почвы Малого Кавказа. Баку, Издво АН АЗ ССР, 1966. $322 \mathrm{c}$.

6. Салаев М. Э. Диагностика и классификация почв Азербайджана. Баку, Наука, 1991. 240 с.

7. Саламов Г. А. Изучение распространения и генетико-производственных особенностей лесных почв в северо-западной части Малого Кавказа. Отчет ИГ 1981$1983,173 \mathrm{c}$.

8. Шептухов В.Н. О совершенствовании оценки процессов деградации почв // Почвоведение, 1997, № 7 , c. $799-805$.

9. Antonello Bonfante, Fabio Terribile, Johan Bouma Refining physical aspects of soio quality and soil health when exploring the effects of soil degradation and climate change on biomass production: an Italian case study. Soil, 2019, v. 5, pp. 1-14, https://doi.org/10.5194/soil-5-1-2019

10. Bogaert J., Ceulemans R., Salvador-Van Eysenrode D. Decision tree algorithm for detection of spatial processes in landscape transformation. Environmental Management, 2004, v. 33(1), pp. 62-73.

11. Mulder P., McGarry D. Soil Erosion Indicators. Part of the Project: "Rural Development Project: Contract 3 Sustainable Pasture, Arable and Forest Land Management - Tajikistan”. Asian Development Bank. Global Environment Facility, 2010.

12. Zheng X., Yuan J., Zhang T., Hao F., Jose S., Zhang S. Soil Degradation and the Decline of Available Nitrogen and Phosphorus in Soils of the Main Forest Types in the Qinling Mountains of China. Forests, 2017, v. 8(11), pp. 460.

\section{REFERENCES}

1. Ishbulatov M. G., Churagulova Z. S. et al. Izmenenie svojstv pochv lesnoj ekosistemy pod vlijaniem antropogennyh nagruzok. [Changes in soil properties of the forest ecosystem under the influence of anthropogenic stresses]. Izvestiya of RAS SamSC, 2011, v. 13, no 1 (5), pp. 1200-1203.

2. Mamedov G.Sh., Yakubov G. Sh. Rukovodstvo po vyjavleniju i kartografirovaniju degradirovannyh zemel', jerozii, zasolenija i drugih prichin dlja podgotovki predlozhenij po ih jeffektivnomu ispol'zovaniju [Guidelines for identifying and mapping degraded lands, erosion, salinization and other reasons for preparing proposals for their effective use]. Baku, 2010. 113 p.

3. Mamedov Z. R. Jekologicheskaja ocenka severo-vostochnogo sklona Malogo Kavkaza [Environmental assessment of the north-eastern slope of the Lesser Caucasu]. Baku, Science, 2014. 206 p.

4. Mirzoev Sh. I. Issledovanie jekologicheskih osobennostej pochv gorno-lesnoj zony na severo-vostochnom sklone Malogo Kavkaza [A study of the ecological characteristics of the soils of the mountain forest zone on the northeastern slope of the Lesser Caucasus]. Account 2005-2006. ANAS warehouse materials, $75 \mathrm{p}$.

5. Salaev M.E. Pochvy Malogo Kavkaza [Soil of the Lesser Caucasus]. Baku: Publishing House of Academy of Sciences of Azerbaijan SSR, 1966. 322 p.

6. Salaev M.E. Diagnostika i klassifikacija pochv Azerbajdzhana [Diagnosis and classification of soils in Azerbaijan]. Baku, Publishing House-Science, 1991, p. 240.

7. Salamov G. A. Izuchenie rasprostranenija i genetiko-proizvodstvennyh osobennostej lesnyh pochv $v$ severo-zapadnoj chasti Malogo Kavkaza [A study of the distribution and genetic-production characteristics of forest soils in the Northern part of the Lesser Caucasus]. Report IG 1981-1983, $173 \mathrm{p}$.

8. Sheptukhov V. N. O sovershenstvovanii ocenki processov degradacii pochv [On improving the assessment of soil degradation processes]. Soil Science, 1997, v. 7, pp. 799-805.

9. Antonello Bonfante, Fabio Terribile, Johan Bouma Refining physical aspects of soio quality and soil health when exploring the effects of soil degradation and climate change on biomass production: an Italian case study. Soil, 2019, v. 5, pp. 1-14, https://doi.org/10.5194/soil-5-1-2019 
10. Bogaert J., Ceulemans R., Salvador-Van Eysenrode D. Decision tree algorithm for detection of spatial processes in landscape transformation. Environmental Management, 2004, v. 33(1), pp. 62-73.

11. Mulder P., McGarry D. Soil Erosion Indicators. Part of the Project: "Rural Development Project: Contract 3 Sustainable Pasture, Arable and Forest Land Management

\section{КОНФЛИКТ ИНТЕРЕСОВ}

Автор декларирует отсутствие явных и потенциальных конфликтов интересов, связанных с публикацией настоящей статьи.

\section{Эюбова Зулейха Ифтихар}

младший научный сотрудник, докторант Института географии им. акад. Г. А. Алиева Национальной академии наук Азербайджана, г. Баку, Азербайджанская Республика, ORCID: https://orcid.org/0000-0003-4209-2217, e-mail: zuzum30@gmail.com
- Tajikistan”. Asian Development Bank. Global Environment Facility, 2010.

12. Zheng X., Yuan J., Zhang T., Hao F., Jose S., Zhang S. Soil Degradation and the Decline of Available Nitrogen and Phosphorus in Soils of the Main Forest Types in the Qinling Mountains of China. Forests, 2017, v. 8(11), pp. 460.

\section{CONFLICT OF INTEREST}

The author declares no information of obvious and potential conflicts of interest related to the publication of this article.

\section{Zuleykha I. Eyubova}

Junior Researcher, Doctoral Candidate at the Geography Institute Acad. H.A. Aliyev ANAS, Baku, Azerbaijan, ORCID: https://orcid.org/0000-0003-4209-2217, e-mail: zuzum30@gmail.com 